\title{
Hyperoxia sensitizes hypoxic HeLa cells to ionizing radiation by downregulating HIF-1 $\alpha$ and VEGF expression
}

\author{
DAN DONG, YAN FU, FENG CHEN, JING ZHANG, HAIYAN JIA, JIA LI, HUAILIN WANG and JIHONG WEN \\ Department of Obstetrics and Gynecology, The First Hospital of Jilin University, Changchun, Jilin 130021, P.R. China
}

Received April 8,2020; Accepted October 2, 2020

DOI: $10.3892 / \mathrm{mmr} .2020 .11700$

\begin{abstract}
The current study investigated whether hyperoxia may reverse hypoxia-induced radioresistance $(\mathrm{RR})$ in cervical cancer. Human HeLa cells exposed to hypoxic, normoxic or hyperoxic conditions were irradiated using X-rays. Cell proliferation and apoptosis were analyzed using MTT assays and flow cytometry. The expression levels of hypoxia-inducible factor-1 $\alpha$ (HIF-1 $\alpha)$, VEGF $_{165}$, VEGFRs, Akt and ERK were measured via western blotting and/or ELISA. The results demonstrated that hypoxia stimulated HIF-1 $\alpha$ and VEGF expression, and induced RR in HeLa cells. The administration of recombinant VEGF or the forced expression of VEGF promoted RR, whereas inactivating HIF-1 $\alpha$ or blocking the VEGF-VEGFR interaction abrogated hypoxia-induced RR. Notably, hyperoxia decreased the level of hypoxia-stimulated HIF-1 $\alpha$ and VEGF, and enhanced radiosensitivity in hypoxic HeLa cells. The results demonstrated that hyperoxia suppressed the hypoxia-activated Akt and ERK signaling pathways in HeLa cells. Therefore, a high $\mathrm{O}_{2}$ concentration may be considered as a radiotherapeutic sensitizer for hypoxic HeLa cells.
\end{abstract}

\section{Introduction}

Cervical cancer has been the second most common gynecological malignancy in women since the 1990s (1) and results in $>300,000$ deaths per year worldwide (2). Radiotherapy is the most frequently used therapeutical modality for cervical cancer (3); however, due to the occurrence of radioresistance (RR), the therapeutic efficacy of radiotherapy is far from satisfactory (4). Therefore, exploring effective and alternative methods to enhance radiosensitivity (RS) is crucial to the clinical radiotherapy of cervical cancer.

Correspondence to: Professor Jihong Wen, Department of Obstetrics and Gynecology, The First Hospital of Jilin University, 71 Xinmin Street, Changchun, Jilin 130021, P.R. China

E-mail: jihongw02@163.com

Key words: cervical cancer, hypoxia, hyperoxia, radiotherapy, HeLa
Intratumoral hypoxia is a typical characteristic of numerous invasive solid tumors (5). It has been proposed that hypoxic tumor cells achieve RR more easily compared with those in a normoxic environment, and therefore, tumor hypoxia has been associated with poor survival outcomes (6,7). Although the application of novel radiosensitizers, including Ro 90-7501, cisplatin (or nedaplatin) and curcumin, have enhanced the radiotherapy efficacy of cervical cancer (8-11), the toxic effects, such as acute hematological and gastrointestinal toxicity, induced by these chemicals are difficult to avoid.

Most tumors contain $\mathrm{O}_{2}$ - and nutrient-deprived compartments (12). The sterilization of tumor cells under hypoxic conditions requires radiation doses that are three times higher than those for cells under normoxic conditions (13). Hyperbaric $\mathrm{O}_{2}$ therapy is an efficient method to cope with the phenomenon of hypoxia by enhancing the $\mathrm{O}_{2}$ load in tumor areas and enhance the response to ionizing radiation (IR) (14-16). Nordsmark et al (17) demonstrated that increased tumor partial $\mathrm{O}_{2}$ pressure enhanced IR response in mammary carcinoma. Pietrofesa et al (18) reported that exposure to the combination of IR $+\mathrm{O}_{2}$ increased DNA damage and cell death compared with the individual exposures to IR or $\mathrm{O}_{2}$ alone. However, how a high concentration of $\mathrm{O}_{2}$ pretreatment affects the efficacy of cervical cancer radiotherapy has not been fully elucidated.

Tumor cells in a hypoxic region adapt to low $\mathrm{O}_{2}$ tension conditions by activating survival factors and cell signaling pathways, such as hypoxia-inducible factor $1 \alpha$ (HIF-1 $\alpha$ ) and VEGF (19). HIF-1 $\alpha$ is one of the most recognized transcription factors used by hypoxic cells in the harsh tumor microenvironment, and it activates $>100$ downstream genes required for tumor survival and progression, including VEGF, erythropoietin and c-MYC (20). The Akt and ERK signaling pathways are two major upstream regulators of HIF-1 $\alpha$. Previous studies have reported that there is an association between the Akt/ERK signaling pathways and HIF-1 $\alpha /$ VEGF expression, which may affect the cellular reaction to radiation, $\mathrm{O}_{2}$ tension and chemical stimuli (21-23). However, the roles that HIF-1 $\alpha$, VEGF and the Akt/ERK signaling pathways serve in cervical cancer radiotherapy remain unclear.

The aim of present study was to investigate how hypoxia, normoxia and hyperoxia affect the efficacy of radiotherapy for cervical cancer and whether hyperoxia can reverse hypoxia-induced IR. 


\section{Materials and methods}

Cell line and culture. Human cervical cancer HeLa cells were purchased from The Cell Bank of Type Culture Collection of the Chinese Academy of Sciences and stored in the laboratory of Department of Obstetrics and Gynecology in the First Hospital of Jilin University. Cells were cultured in DMEM (Thermo Fisher Scientific, Inc.) supplemented with 10\% FBS (HyClone; Cytiva) and 1\% antibiotics (penicillin/streptomycin; Invitrogen; Thermo Fisher Scientific, Inc.) in a humidified $37^{\circ} \mathrm{C}$ incubator with $5 \% \mathrm{CO}_{2}$.

Normoxia, hypoxia, reoxygenation and hyperoxia. For the normoxic culture (Normo), HeLa cells were maintained at $37^{\circ} \mathrm{C}$ in a humidified $\mathrm{O}_{2}(20 \%), \mathrm{CO}_{2}(5 \%)$ and $\mathrm{N}_{2}(75 \%)$ atmosphere (Thermo Fisher Scientific, Inc.). For the hypoxic culture (Hypo), cells were cultured at $37^{\circ} \mathrm{C}$ in a humidified $\mathrm{O}_{2}(1 \%), \mathrm{CO}_{2}(5 \%)$ and $\mathrm{N}_{2}(94 \%)$ incubator (Thermo Fisher Scientific, Inc.) for $12 \mathrm{~h}$. For reoxygenation (Reoxy), cells were cultured under hypoxic conditions at $37^{\circ} \mathrm{C}$ for $12 \mathrm{~h}$ followed by normoxic conditions at $37^{\circ} \mathrm{C}$ for $2 \mathrm{~h}$. For the hyperoxic culture (Hyper), cells were placed in a $\mathrm{CO}_{2}(5 \%)$ and $\mathrm{O}_{2}(95 \%)$ chamber (ProOX P360 $\mathrm{O}_{2}$ controller and chamber; BioSpherix, Ltd.) at $37^{\circ} \mathrm{C}$ for $2 \mathrm{~h}$ (24). In order to investigate the effects of hypoxia, reoxygenation and hyperoxia on IR, HeLa cells were divided into the following treatment groups: i) IR-alone (IR); ii) hypoxia followed by IR (Hypo + IR); iii) hyperoxia followed by IR (Hyper + IR); iv) hypoxia followed by reoxygenation and IR (Hypo + Reoxy + IR); and v) hypoxia followed by hyperoxia and IR (Hypo + Hyper + IR).

$I R$. Monolayer HeLa cells were seeded into six-well plates $\left(1 \times 10^{5}\right.$ cells per well) or $10-\mathrm{cm}$ dishes $\left(6 \times 10^{5}\right.$ cells per dish) to achieve $70 \%$ confluency and were then exposed to X-rays at a dose rate of $1 \mathrm{~Gy} / \mathrm{min}$ in a X-RAD 320 (Precision X-RAD; Precision X-Ray, Inc.). A moderate X-ray dose of 6 Gy was applied, according to previous studies $(25,26)$. Following IR, cells were cultured for $24 \mathrm{~h}$ at $37^{\circ} \mathrm{C}$ in a humidified $\mathrm{O}_{2}(20 \%)$, $\mathrm{CO}_{2}(5 \%)$ and $\mathrm{N}_{2}(75 \%)$ atmosphere until cell proliferation or apoptosis tests were conducted. For other experiments (e.g. western blotting), cells were harvested immediately. Control groups were treated similarly; however, these cells did not undergo IR.

Plasmid and cell transfection. Coding sequence of $\mathrm{VEGF}_{165}$ was synthesized (Sangon Biotech Co., Ltd.) and cloned into pcDNA3.1 vector (Invitrogen; Thermo Fisher Scientific, Inc.) to form a pCDNA3.1-VEGF plasmid. For the forced expression of $\mathrm{VEGF}_{165}$ (feVEGF) in HeLa cells, $2 \mu \mathrm{g}$ plasmid DNA and blank control vectors were transfected using Lipofectamine ${ }^{\circledR} 3000$ (Invitrogen), according to the manufacturer's protocol. Western blotting or IR (feVEGF + IR) were conducted at $48 \mathrm{~h}$ post-transfection.

$V E G F / V E G F R$ stimulation and neutralization tests. For the VEGF stimulation test, $10 \mathrm{ng} / \mathrm{ml}$ recombinant human $V_{E G F} F_{165}$ (reVEGF, cat. no. ab9571; Abcam) (27) was added to cell culture media $\left(37^{\circ} \mathrm{C}, 5 \% \mathrm{CO}_{2}\right)$ at $2 \mathrm{~h}$ prior to IR (reVEGF + IR). For the ligand-receptor neutralization test, $25 \mu \mathrm{g} / \mathrm{ml}$ VEGF,
$30 \mu \mathrm{g} / \mathrm{ml}$ VEGFR1 or $500 \mathrm{ng} / \mathrm{ml}$ VEGFR2 neutralization antibodies (cat. nos. AF293, AF321 and MAB3572; R\&D Systems China Co., Ltd.) were added to cell culture media $\left(37^{\circ} \mathrm{C}, 5 \% \mathrm{CO}_{2}\right)$ at $2 \mathrm{~h}$ prior to IR, as previously described, and the manufacturer's protocol $(28,29)$. Human IgG1 $\kappa$ (cat. no. ab206200; Abcam) was used as the isotype control (IgG1 $\kappa+$ Hypo + IR).

Inhibitors. To inhibit HIF-1 $\alpha$ function, $100 \mathrm{nM}$ echinomycin (30) (Merck KGaA) was added to cell culture media $\left(37^{\circ} \mathrm{C}, 5 \% \mathrm{CO}_{2}\right) 2 \mathrm{~h}$ prior to hypoxic exposure. To block the Akt and ERK signaling pathways, $50 \mu \mathrm{M}$ LY294002 and $20 \mu \mathrm{M}$ U0126 (Beyotime Institute of Biotechnology) were added to cell culture media $\left(37^{\circ} \mathrm{C}, 5 \% \mathrm{CO}_{2}\right) 2 \mathrm{~h}$ prior to IR as previously described $(31,32)$.

ELISA. The level of secreted VEGF in the medium was quantified using a human VEGF Quantikine ELISA kit (cat. no. DVE00; R\&D Systems, Inc.). According to the manufacturer's protocol, the supernatant of $\geq 1 \times 10^{5} \mathrm{HeLa}$ cells (or treated HeLa cells) were collected and centrifuged at $4^{\circ} \mathrm{C}$ and $1,000 \mathrm{x} \mathrm{g}$ for $15 \mathrm{~min}$ to remove debris and particulates. The absorbance at $450 \mathrm{~nm}\left(\mathrm{~A}_{450}\right)$, which is proportional to VEGF concentration, was determined using an ELISA reader (Synergy H1 Hybric Multi-Mode Reader; BioTek Instruments, Inc.).

VEGFR2 was quantified using a human VEGF R2/KDR Quantikine ELISA kit (cat. no. DVR200; R\&D Systems, Inc.). According to the manufacturer's protocol, $\geq 1 \times 10^{5}$ cells were washed 3 times in cold PBS and resuspended in $1 \mathrm{ml}$ lysis buffer. The lysate was incubated at RT for $1 \mathrm{~h}$ with gentle agitation and centrifuged at $1,000 \mathrm{x}$ g for $15 \mathrm{~min}$ at RT. $\mathrm{A}_{450}$ was determined as aforementioned.

Cell proliferation inhibition assay. Cell proliferation was determined using a standard spectrophotometric MTT assay. HeLa cells were seeded at a density of 5,000 cells/well into a 96-well plate and underwent Hypo, Reoxy, Hyper and/or IR, as aforementioned. Subsequently, cells were cultured at $37^{\circ} \mathrm{C}$ for another $24 \mathrm{~h}$ in normal $\mathrm{O}_{2}$ condition and incubated at $37^{\circ} \mathrm{C}$ for $4 \mathrm{~h}$ with MTT solution $(5 \mathrm{mg} / \mathrm{ml}$, Sigma-Aldrich; Merck KGaA). The cell supernatant was carefully aspirated, and the precipitate was dissolved using $200 \mu 1$ DMSO (Sigma-Aldrich; Merck KGaA) at $37^{\circ} \mathrm{C}$ for $10 \mathrm{~min} . \mathrm{A}_{490}$ was determined as aforementioned. The cell proliferation inhibition rate $(\%)$ of each group was defined as follows: $\left(\mathrm{A}_{490}\right.$ of the experimental group- $\mathrm{A}_{490}$ of the control group) $/ \mathrm{A}_{490}$ of the control group.

Apoptosis assay. Apoptosis was determined using an Annexin V-FITC Apoptosis Detection kit (cat. no. 556547; BD Biosciences). According to the manufacturer's protocol, $1 \times 10^{5} \mathrm{HeLa}$ cells were washed with cold PBS and centrifuged at RT and $200 \mathrm{x}$ g for $5 \mathrm{~min}$. The cell pellet was resuspended and incubated in $50 \mu \mathrm{l}$ Annexin V solution containing $5 \mu \mathrm{l}$ PI and $5 \mu \mathrm{l}$ Annexin V-FITC at RT for $15 \mathrm{~min}$. Data acquisition and analysis were performed using flow cytometry (FACScan; BD Biosciences) and FlowJo software (version 10.0; FlowJo LLC). Results for early and late apoptosis were combined as the total amount of apoptosis. 
Western blotting. Total protein was extracted from HeLa or transfected HeLa cells using RIPA lysis buffer (Beyotime Institute of Biotechnology) supplemented with cocktail protease inhibitors [Roche Diagnostics (Shanghai) Co., Ltd.] and quantified using a Bradford dye binding assay kit (Beyotime Institute of Biotechnology) according to the manufacturer's protocol. Each sample was loaded with $20 \mu \mathrm{g}$ protein/lane on a $12 \%$ gel and separated via SDS-PAGE. Samples were electrophoretically transferred to a PVDF membrane (EMD Millipore), which was then blocked with 5\% skimmed milk in PBS at RT for $1 \mathrm{~h}$ and incubated with the following primary antibodies against VEGF (1:1,500; cat. no. AF-293-SP; R\&D Systems, Inc.), HIF-1 $\alpha$ (1:1,000; cat. no. ab1; Abcam), ERK1/2 (1:1,000; cat. no. 4696; Cell Signaling Technology, Inc.), phosphorylated (p-)ERK1/2 (1:1,000; cat. no. 4370; Cell Signaling Technology, Inc.), Akt (1:1,000; cat. no. 4685; Cell Signaling Technology, Inc.), p-Akt (1:1,000; cat. no. 4060; Cell Signaling Technology, Inc.) and $\beta$-actin $(1: 1,500$; cat. no. sc-47778; Santa Cruz Biotechnology, Inc.) at $37^{\circ} \mathrm{C}$ for $1 \mathrm{~h}$. Membranes were then incubated with goat anti-mouse, goat anti-rabbit or rabbit anti-goat (1:3,000; cat. nos. sc-2005, sc-2004 and sc-2768, respectively; Santa Cruz Biotechnology, Inc.) IgG peroxidase-conjugated secondary antibodies at $37^{\circ} \mathrm{C}$ for $45 \mathrm{~min}$. Immunoreactivity was visualized using an ECL detection kit (EMD Millipore). Densitometric analysis was performed using Quantity One software (version 4.6; Bio-Rad Laboratories, Inc.).

Statistical analysis. All experiments were repeated $\geq 3$ times. Data were analyzed using SPSS software (version 17.0; SPSS, Inc.) and presented as the mean \pm SD. Statistical analysis was performed using Student's unpaired t-test or one-way ANOVA followed by Fisher's Least Significant Difference, Bonferroni or Sidak post-hoc tests. $\mathrm{P}<0.05$ was considered to indicate a statistically significant difference.

\section{Results}

Hyperoxic treatment enhances $R S$ in hypoxic HeLa cells. The cellular inhibition rates were as follows: IR, $51.36 \%$; Hypo + IR, 26.61\%; Hyper + IR, 49.42\%; Hypo + Reoxy + IR, 28.94\%; and Hypo + Hyper + IR,45.96\% (Fig. 1). These data indicated that hypoxia promoted RR in HeLa cells and that hyperoxia sensitized the hypoxic HeLa cells to IR; however, reoxygenation did not sensitize cells to IR. There is a possibility that extending the reoxygenation time may achieve the same effect as the cells being exposed to hyperoxia for $2 \mathrm{~h}$. However, this hypothesis requires further experimental verification.

Hypoxia pretreatment significantly decreased the cellular apoptosis rates compared with the IR-alone (15.91\% vs. $25.59 \%$; Fig. 2). However, hypoxic cells which subsequently underwent hyperoxia exhibited a significant increase in RS and cellular apoptosis rate $(27.26 \%)$ compared with cells which underwent reoxygenation $(18.75 \%)$ or hypoxia-alone $(15.91 \%)$.

Hyperoxia downregulates hypoxia-stimulated HIF-1 $\alpha$ and $V E G F$ expression. Hypoxia has been reported to stimulate VEGF expression, particularly in cancer cells (33). Western blotting showed that hypoxia treatment upregulated HIF-1 $\alpha$ levels 2-fold and VEGF levels 2.3-fold compared with

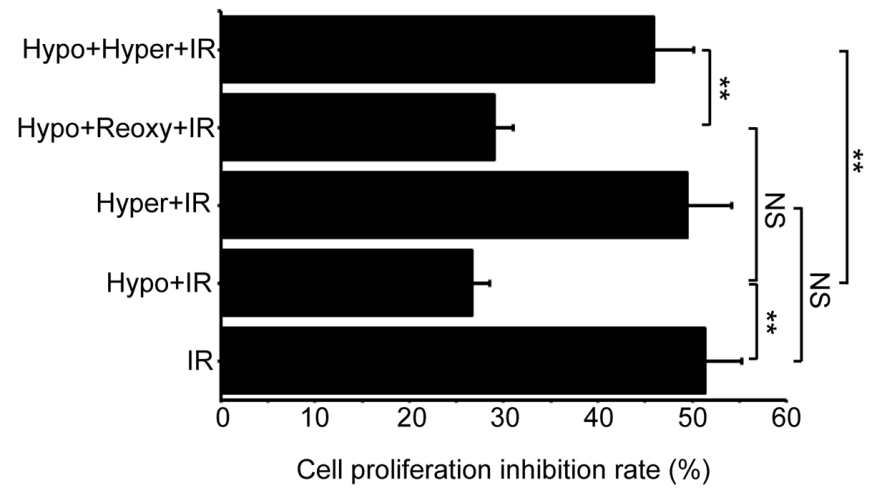

Figure 1. Hyperoxic treatment sensitizes hypoxic HeLa cells to IR. HeLa cells underwent Hypo, Hyper, Hypo + Reoxy and Hypo + Hyper and were irradiated by IR. Cell proliferation inhibition tests indicated that hypoxia promotes RR in HeLa cells, whereas hyperoxia following hypoxia treatment neutralizes hypoxia-induced RR. ANOVA followed by Bonferroni and Sidak post-hoc tests. ${ }^{* *} \mathrm{P}<0.01$. IR, ionizing radiation; Hypo, hypoxia; Hyper, hyperoxia; Reoxy, reoxygenation; NS, not significant.

cells cultured in normal $\mathrm{O}_{2}$ (Fig. 3A and B). Reoxygenation decreased HIF-1 $\alpha$ levels in hypoxic cells to a similar level as the untreated cells but did not affect VEGF levels (Fig. 3A and B). By contrast, hyperoxia decreased both the HIF-1 $\alpha$ and VEGF levels in hypoxic cells (Fig. 3A and B). ELISA indicated that reoxygenation or hyperoxia decreased secretory VEGF levels in hypoxic cells (Fig. 3C).

VEGF enhances RR. VEGF has been reported to be involved in hypoxia-induced RR in HeLa cells (34). Therefore, the current study treated HeLa cells with $10 \mathrm{ng} / \mathrm{ml} \mathrm{reVEGF}$ or feVEGF to HeLa cells. Western blotting showed that VEGF levels increased 1.62-fold in HeLa transfectants (Fig. 4A). Cell apoptosis tests were conducted at $24 \mathrm{~h}$ post-IR; the apoptosis rates of the reVEGF and feVEGF treatment groups were $18.88 \%$ and $16.29 \%$, respectively, compared with $27.16 \%$ in the untreated group (IR-alone) (Fig. 4B). These results suggested that reVEGF and feVEGF elevated the RR of HeLa cells.

Blocking the VEGF-VEGFR2 interaction decreases hypoxia-induced $R R$. VEGFRs are required for VEGF-based signal transfer (35). The current study used VEGF, VEGFR1 and VEGFR2 neutralization antibodies to verify whether the VEGF-VEGFR interaction is implicated in the hypoxia-induced RR. As presented in Fig. 5, treatment with VEGF and VEGFR2 neutralization antibodies significantly promoted IR-induced apoptosis (23.79 and 25.00\%) compared with the Hypo + IR group (17.61\%). However, administration of VEGFR1 neutralization antibodies did not significantly affect IR-induced apoptosis. These data indicated that VEGF may induce RR through interaction with VEGFR2, but not VEGFR1.

HIF-1 $\alpha$ inactivation suppresses VEGF and VEGFR2 expression, and increases $R S$ in hypoxic HeLa cells. Since the aforementioned results demonstrated that HIF-1 $\alpha$ levels paralleled those of VEGF following hypoxic and hyperoxic treatments, it was hypothesized that HIF-1 $\alpha$ may interact with VEGF and function collectively to induce 

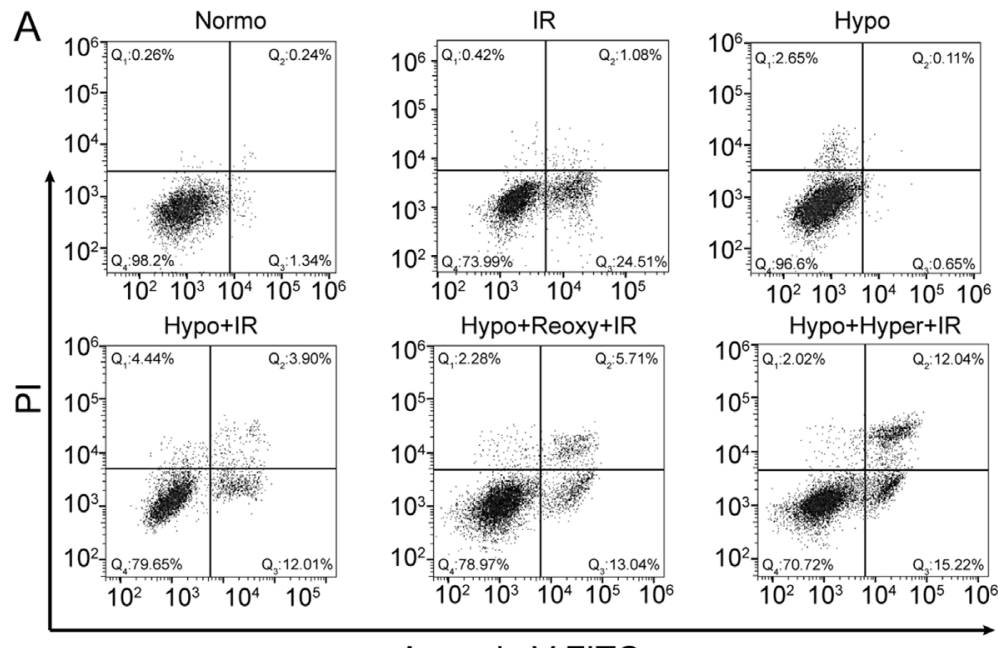

Annexin V-FITC

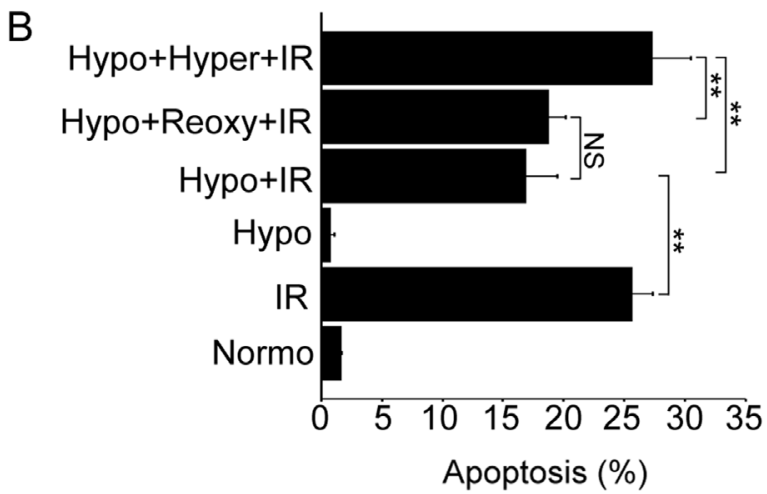

Figure 2. Hyperoxia promotes IR-induced apoptosis in hypoxic HeLa cells. Cells underwent Hypo, Hyper, Hypo + Reoxy and Hypo + Hyper and were irradiated by IR. (A) Cellular apoptosis was measured via flow cytometry and (B) cellular apoptosis rates of the different groups were compared. ANOVA followed by Bonferroni and Sidak post-hoc tests. ${ }^{* *} \mathrm{P}<0.01$. IR, ionizing radiation; normo, normoxia; Hypo, hypoxia; Reoxy, reoxygenation; Hyper, hyperoxia; IR, ionizing radiation; NS, not significant.
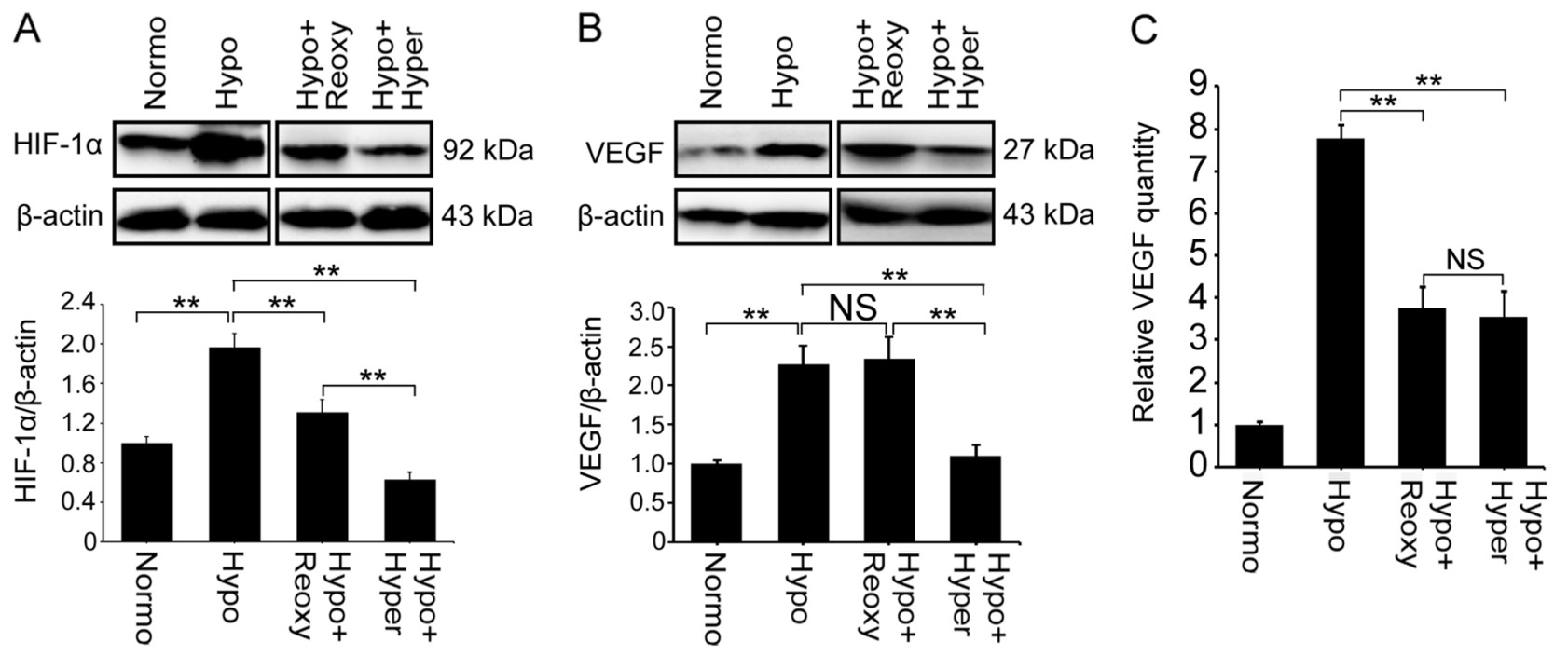

Figure 3. Hyperoxia downregulates hypoxia-stimulated HIF-1 $\alpha$ and VEGF expression. Protein expression levels of (A) HIF-1 $\alpha$ and (B) VEGF were analyzed via western blotting and relative band density was measured. $\beta$-actin was used as the internal control. (C) Secreted VEGF was quantified using ELISA. ANOVA followed by Bonferroni and Sidak post-hoc tests. ${ }^{* *} \mathrm{P}<0.01$. Normo, normoxia; Hypo, hypoxia; Reoxy, reoxygenation; Hyper, hyperoxia; NS, not significant.

RR in hypoxic HeLa cells. Therefore, the HIF-1 $\alpha$ inhibitor echinomycin was added to the cell media prior to hypoxia treatment. The results demonstrated that the levels of VEGF
(Fig. 6A) and VEGFR2 (Fig. 6B) in cells pretreated with echinomycin were significantly decreased compared with those in hypoxic cells. Furthermore, the results revealed that 

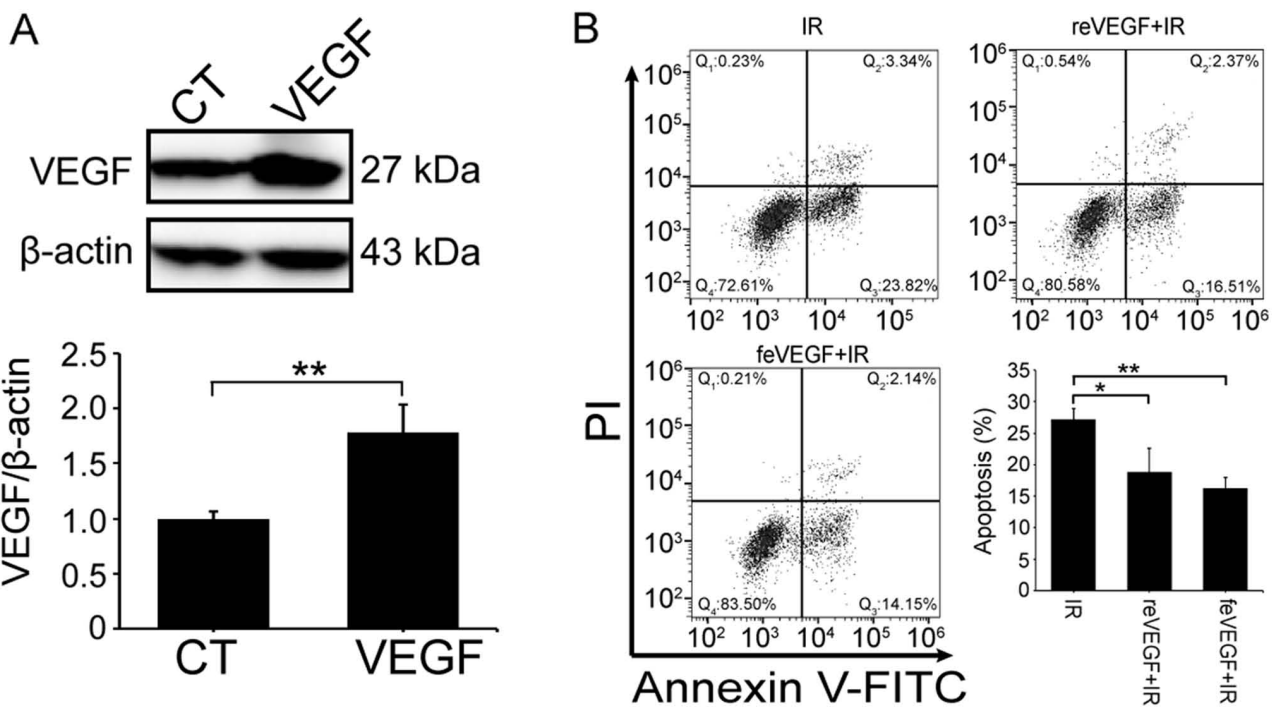

Figure 4. Treatment with reVEGF or feVEGF enhances the radioresistance of HeLa cells. (A) Western blotting was performed to verify the forced expression of exogenous VEGF. (B) Flow cytometry results demonstrated that treatment with reVEGF or feVEGF decreased IR-induced apoptosis. Student's t-test or one-way ANOVA followed by Fisher's Least Significant Difference test. "P $<0.05$ and ${ }^{* * *} \mathrm{P}<0.01$. reVEGF, recombinant VEGF; feVEGF, forced expression of VEGF; IR, ionizing radiation; normo, normoxia; CT, control.
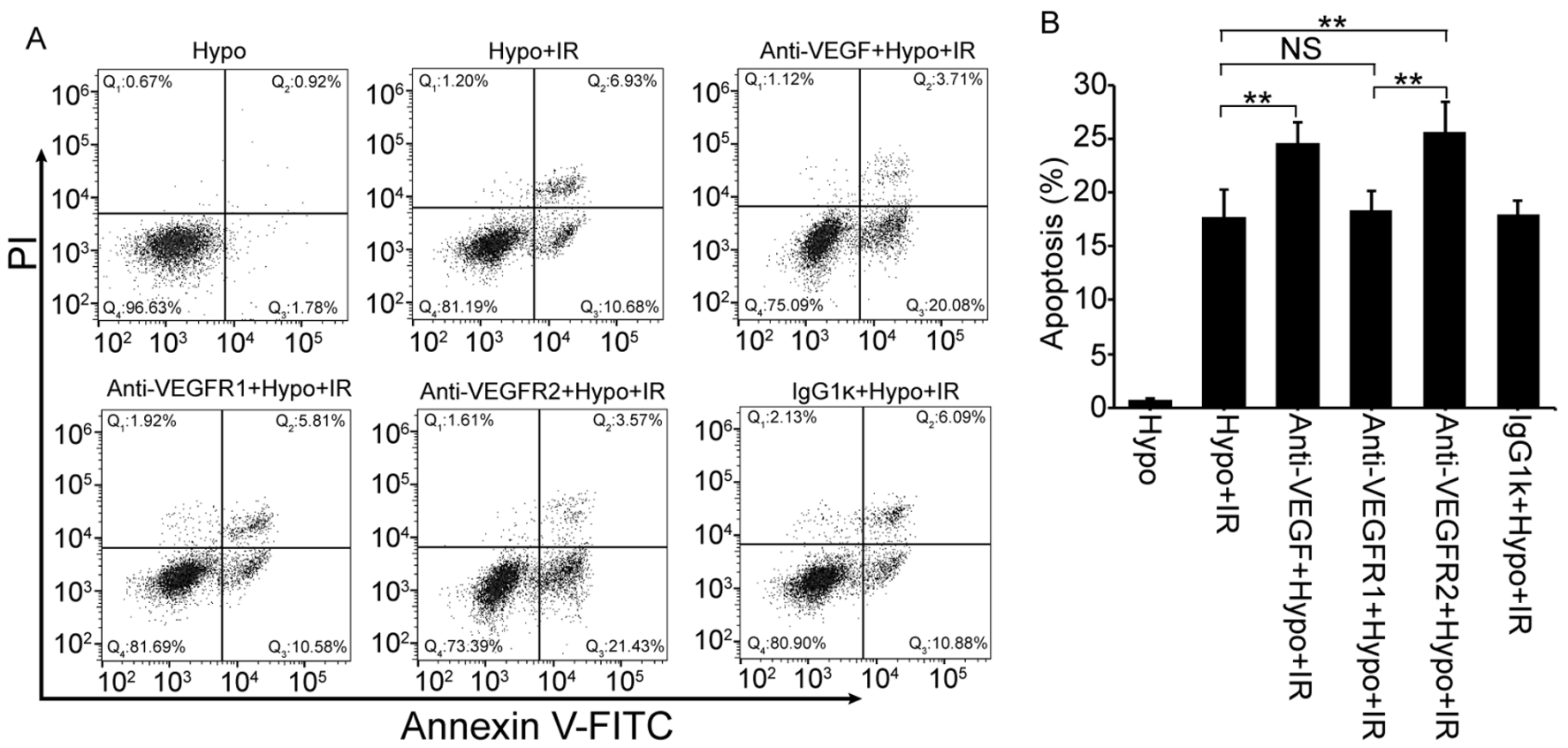

Figure 5. Blocking the VEGF-VEGFR2 interaction decreases hypoxia-induced radioresistance. VEGF and VEGFR2 neutralization antibodies were added to the cell culture media to block the VEGF-VEGFR interaction. (A and B) Flow cytometry results indicated that administration of the VEGF neutralization antibody and VEGFR2 neutralization antibody promoted IR-induced apoptosis in hypoxic HeLa cells. However, administration of the VEGFR1 neutralization antibody did not affect IR-induced apoptosis. ANOVA followed by Bonferroni and Sidak post-hoc tests. ${ }^{* *} \mathrm{P}<0.01$. IR, ionizing radiation; Hypo, hypoxia.

the administration of echinomycin promoted IR-induced apoptosis in hypoxic HeLa cells (Fig. 6C). The cellular apoptosis rate in the Hypo + echinomycin + IR group increased by 1.7 -fold compared with the Hypo + IR group $(27.72 \%$ vs. $16.62 \%$, respectively; Fig. 6D).

Hyperoxia enhances RS by suppressing the Akt and ERK signaling pathways. It has been reported that hyperactivation of Akt and ERK is associated with RR (36-38). The results of the current model detected the activation of Akt and ERK1/2.
Western blotting results indicated that the levels of p-Akt (Fig. 7A) and p-ERK1/2 (Fig. 7B) were significantly increased in hypoxic HeLa cells compared with those in cells cultured in normal $\mathrm{O}_{2}$, whereas hyperoxia exposure significantly suppressed the phosphorylation of Akt and ERK1/2 induced by hypoxia. Furthermore, LY294002 (Fig. 7C) and U0126 (Fig. 7D) were used to block the PI3K/Akt and MAPK/ERK pathways, respectively, and the results demonstrated that hypoxia-induced RR was decreased and the IR-induced apoptosis was increased using the inhibitors. 

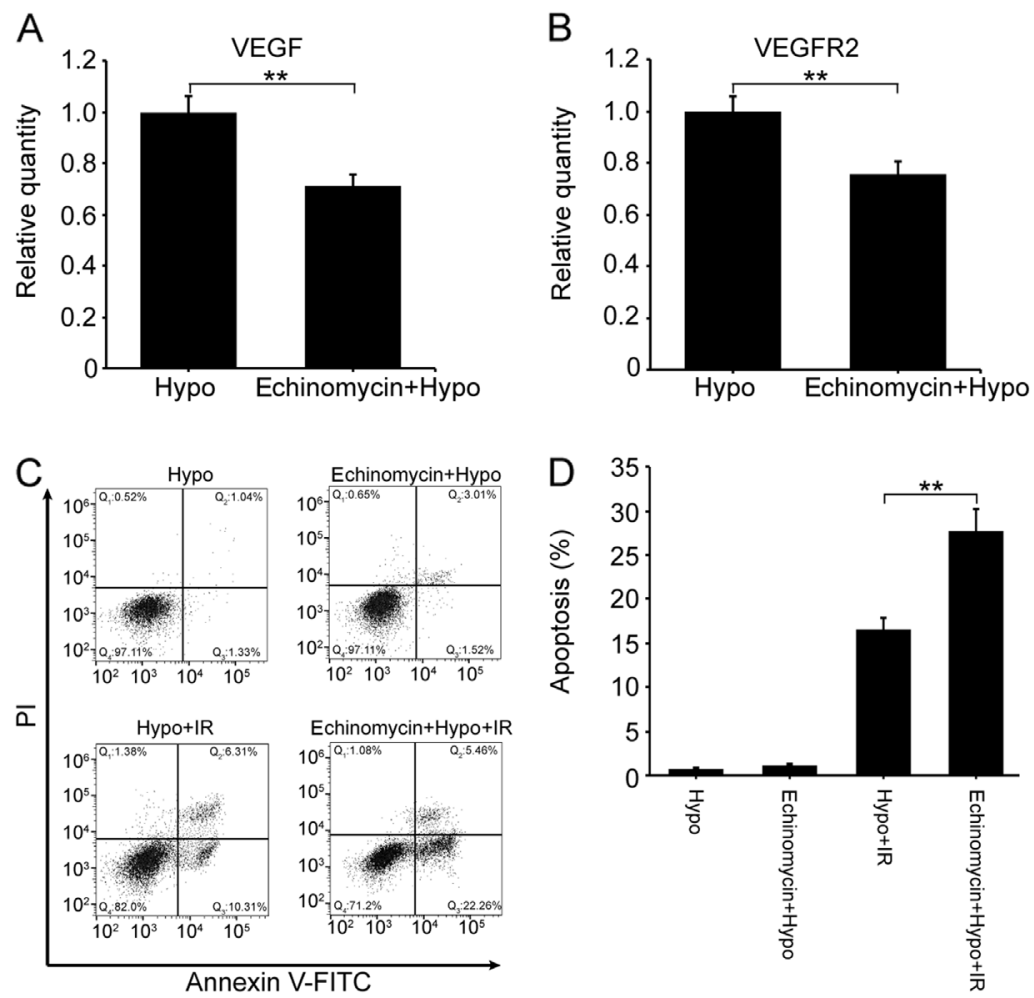

Figure 6. HIF-1 $\alpha$ inhibition suppresses VEGF and VEGFR2 expression, and promotes IR-induced apoptosis in hypoxic HeLa cells. To investigate the association between HIF- $1 \alpha$ and the VEGF/hypoxia-induced RR axis, echinomycin was used to inhibit HIF-1 $\alpha$ function. ELISA results demonstrated that (A) VEGF and (B) VEGFR2 expression in hypoxic cells were decreased using echinomycin. (C and D) Administration of echinomycin promoted IR-induced apoptosis in hypoxic HeLa cells. Student's t-test or one-way ANOVA followed by Bonferroni and Sidak post-hoc tests. ${ }^{* *} \mathrm{P}<0.01$. HIF-1 $\alpha$, hypoxia-inducible factor-1 $\alpha$; IR, ionizing radiation; Hypo, hypoxia.

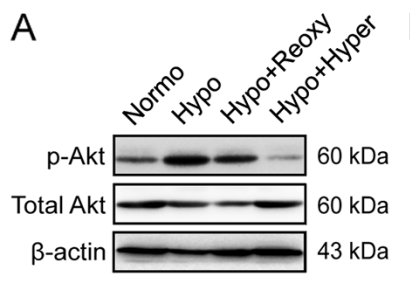

B
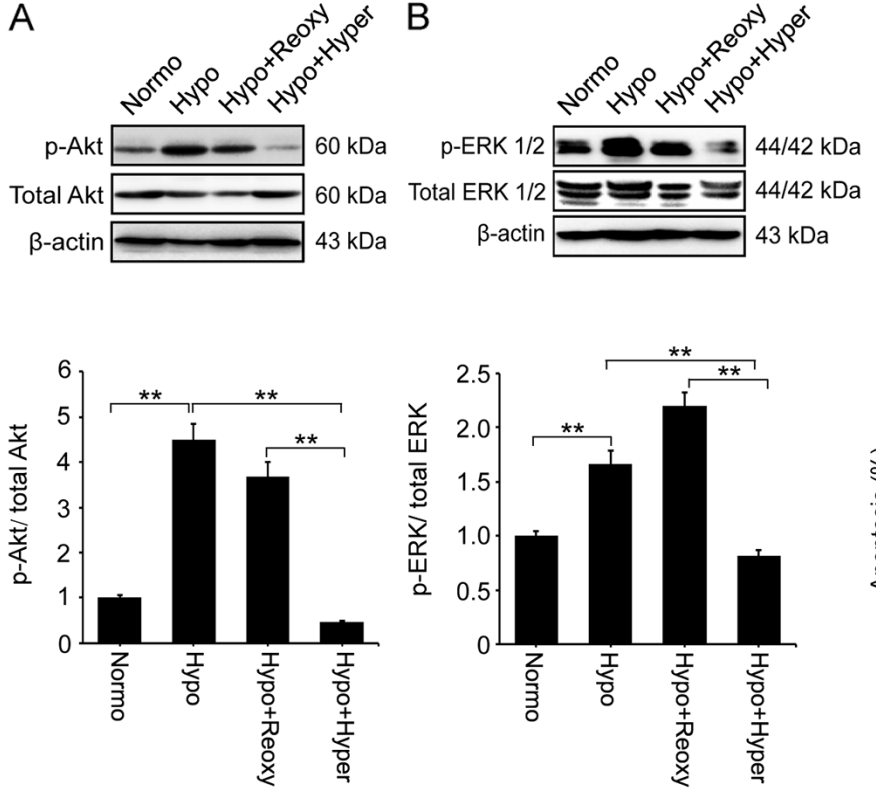

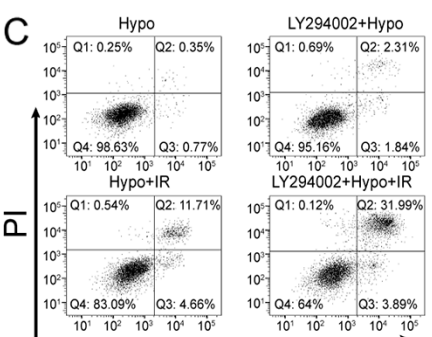

Annexin V-FITC

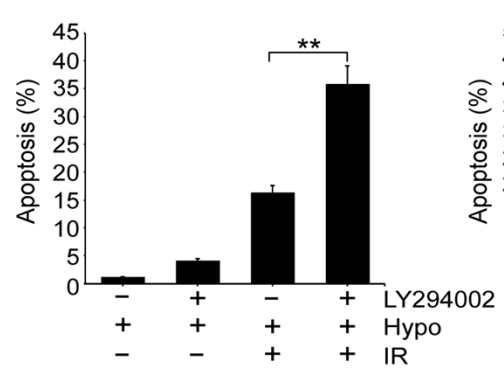

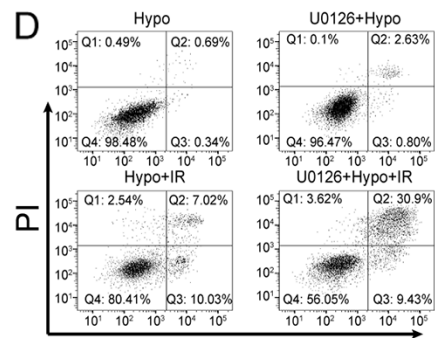

Annexin V-FITC

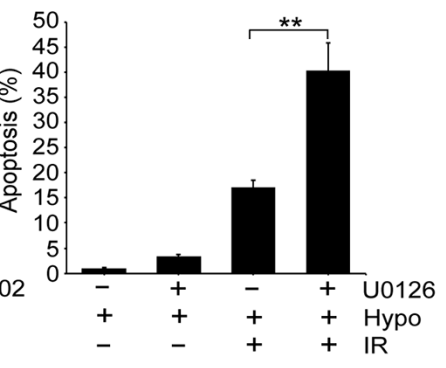

Figure 7. Hyperoxia enhances radiosensitivity by suppressing the Akt and ERK signaling pathways. Western blotting analysis revealed that (A) Akt and (B) ERK were hyperactivated in hypoxic HeLa cells, whereas hyperoxia abrogated the phosphorylation of Akt and ERK1/2. Flow cytometry results indicated that the (C) PI3K/Akt pathway inhibitor LY294002 and (D) MAPK/ERK pathway inhibitor U0126 promoted IR-induced apoptosis. ANOVA followed by Bonferroni and Sidak post-hoc tests. ${ }^{* *} \mathrm{P}<0.01$. IR, ionizing radiation; Normo, normoxia; Hypo, hypoxia; Reoxy, reoxygenation; Hyper, hyperoxia; p-, phosphorylated.

\section{Discussion}

Most, if not all, solid tumors exist in an anoxic microenvironment due to insufficient blood supply (39). To survive in hypoxic conditions, tumor cells gradually adapt to hypoxic stress through regulation of numerous genes, such as HIF-1 $\alpha$, VEGF, insulin-like growth factor $\alpha$ and transforming growth factor $\alpha$, which are associated with tumor cell proliferation, 
apoptosis, chemotherapy resistance and radiotherapy resistance (40).

Tumor hypoxia is a major contributing factor for the failure of anticancer therapies, including radiotherapy (7). It has been proposed that cells under hypoxic stress are more likely to generate $\mathrm{RR}$ due to the lack of $\mathrm{O}_{2}$ as a source of radiation-induced radicals and DNA damage (41). By contrast, increasing $\mathrm{O}_{2}$ pressure within the tumor can overcome hypoxia-induced RR (42). Pietrofesa et al (18) demonstrated that the combination of hyperoxia and IR increased cell death and DNA damage compared with hyperoxia or IR alone in mouse lung cells.

Mammalian cells respond to $\mathrm{O}_{2}$ deprivation by mobilizing multiple intracellular signal transduction pathways, including HIF family-depending pathways (5). HIF-VEGF axis-mediated cell survival and angiogenesis are implicated in the radiation response in tumors. Fu et al (34) reported that hypoxic conditions enhance the RR of HeLa cells dependent on HIF-1 $\alpha$ by elevating VEGF expression and inhibiting p53 expression. Gorski et al (43) indicated that IR-induced VEGF expression may contribute to the protection of tumor blood vessels from cytotoxicity-mediated radiation and, thereby, to tumor RR. The results of the current study confirmed that hypoxia induced $\mathrm{RR}$ in cervical cancer cells via the activation of HIF-1 $\alpha$ and VEGF. Administration of recombinant VEGF or introduction of exogenous VEGF increased RR in HeLa cells. By contrast, inactivation of a HIF-1 $\alpha$ or blockage of the VEGF-VEGFR interaction abrogated hypoxia-induced RR. According to the present results, it was hypothesized that tumor cells may secrete VEGF to build blood vessels and increase $\mathrm{O}_{2}$ and nutrients supply in order to survive IR-mediated cytotoxicity.

VEGFR1 and VEGFR2 have highly homologous structures; however, their biological functions differ (44). VEGFR2 is implicated in pathological and physiological angiogenesis, whereas VEGFR1 acts as a decoy receptor that limits VEGFR2 activation $(45,46)$. Ding et al $(47)$ reported that silencing of HIF-1 $\alpha$ promoted cell apoptosis and inhibited cell invasion by downregulating VEGF and VEGFR2 expression in thyroid cancer. The results of the current study demonstrated that VEGF may function as an IR-resistant factor through interaction with VEGFR2. Additionally, inhibition of HIF-1 $\alpha$ may abrogate hypoxia-induced RR through the downregulation of VEGF and VEGFR2 expression. The present findings indicated that the HIF- $1 \alpha-\mathrm{VEGF}$ axis may serve an important role in regulating the response of hypoxic cervical cancer cells to IR.

The results of the present study demonstrated that hyperoxia treatment significantly sensitized hypoxic HeLa cells to IR and promoted cellular apoptosis. To gain further insight into the molecular mechanism contributing to this phenomenon, the activation of the Akt and ERK signaling pathways was detected, and the results revealed that hypoxia treatment increased the protein expression levels of p-Akt and p-ERK, whereas hyperoxia abrogated hypoxia-activated p-Akt and p-ERK. Additionally, the administration of Akt and ERK pathway inhibitors significantly decreased hypoxia-induced RR. Gupta et al (48) demonstrated that VEGF significantly enhanced the survival of vein endothelial cells in radiotherapy via the activation of MEK and ERK. Additionally, Chen et al (49) reported that antrocin synergistically induced cell apoptosis and inhibited cell proliferation in radioresistant prostate cancer cells by suppressing the Akt and ERK signaling pathways. The current study indicated that hyperoxia may function as a radiosensitizer by suppressing the hypoxia-induced hyperactivation of the Akt and ERK signaling pathways. However, to validate IR-induced cellular apoptosis, detection of the changes of additional apoptosis markers, including p53, poly (ADP-ribose) polymerase, the caspase cascade and the Bcl-2 family (50-52), should be investigated in future work.

In our previous work, different tumor cell lines were investigated; these cell lines exhibited different sensitivity to IR and $\mathrm{O}_{2}$ (data not shown). Therefore, there may be a tumor type-specific association among RR, the HIF- $1 \alpha$-VEGF axis and hyperoxic sensitization. The present study only reported the data from HeLa cells, as HeLa cells are the most commonly used cell model for the research of cervical cancer. However, to obtain a more comprehensive and solid conclusion, further experiments using more cervical cancer cell lines and in vivo assays are required.

In conclusion, the current investigation demonstrated that hyperoxia may be considered as a radiotherapeutic sensitizer for hypoxic HeLa cells.

\section{Acknowledgements}

Not applicable.

\section{Funding}

This study was supported by Jilin Patent Biotechnology Development Co., Ltd. (grant no. 2020YX016).

\section{Availability of data and materials}

The datasets used and/or analyzed during the current study are available from the corresponding author on reasonable request.

\section{Authors' contributions}

JW and DD wrote the manuscript and performed hypoxia and hyperoxia culturing, cell irradiation, cell proliferation and apoptosis detection. YF contributed to the experimental design. FC and JZ performed plasmid construction experiments. HJ and JL performed the ELISA and western blotting experiments. HW performed the antibody neutralization tests and contributed to statistical analysis. All authors read and approved the final manuscript.

\section{Ethics approval and consent to participate}

Not applicable.

\section{Patient consent for publication}

Not applicable.

\section{Competing interests}

The authors declare that they have no competing interests. 


\section{References}

1. Wu WJ, Shen Y, Sui J, Li CY, Yang S, Xu SY, Zhang M, Yin LH, $\mathrm{Pu}$ YP and Liang GY: Integrated analysis of long noncoding RNA competing interactions revealed potential biomarkers in cervical cancer: Based on a public database. Mol Med Rep 17: 7845-7858, 2018

2. Cohen PA, Jhingran A, Oaknin A and Denny L: Cervical cancer. Lancet 393: 169-182, 2019.

3. Lin CL, Lee CH, Chen CM, Cheng CW, Chen PN, Ying TH and Hsieh YH: Protodioscin induces apoptosis through ROS-mediated endoplasmic reticulum stress via the JNK/p38 activation pathways in human cervical cancer cells. Cell Physiol Biochem 46: 322-334, 2018.

4. Pranatharthi A, Thomas P, Udayashankar AH, Bhavani C, Suresh SB, Krishna S, Thatte J, Srikantia N, Ross CR and Srivastava S: RhoC regulates radioresistance via crosstalk of ROCK2 with the DNA repair machinery in cervical cancer. J Exp Clin Cancer Res 38: 392, 2019.

5. Liu C, Lin Q and Yun Z: Cellular and molecular mechanisms underlying oxygen-dependent radiosensitivity. Radiat Res 183: 487-496, 2015.

6. Hennessey D, Martin LM, Atzberger A, Lynch TH, Hollywood D and Marignol L: Exposure to hypoxia following irradiation increases radioresistance in prostate cancer cells. Urol Oncol 31: 1106-1116, 2013

7. Hong BJ, Kim J, Jeong H, Bok S, Kim YE and Ahn GO: Tumor hypoxia and reoxygenation: The yin and yang for radiotherapy. Radiat Oncol J 34: 239-249, 2016.

8. Candelaria M, Garcia-Arias A, Cetina L and Duenas-Gonzalez A: Radiosensitizers in cervical cancer. Cisplatin and beyond. Radiat Oncol 1: 15, 2006

9. Tamari K, Sano K, Li Z, Seo Y, Otani K, Tatekawa S, Toratani M Takaoka Y, Takahashi Y, Minami K, et al: Ro 90-7501 is a novel radiosensitizer for cervical cancer cells that inhibits ATM phosphorylation. Anticancer Res 39: 4805-4810, 2019.

10. Mabuchi S and Kimura T: Nedaplatin: A radiosensitizing agent for patients with cervical cancer. Chemother Res Pract 2011: 963159, 2011

11. Javvadi P, Segan AT, Tuttle SW and Koumenis C: The chemopreventive agent curcumin is a potent radiosensitizer of human cervical tumor cells via increased reactive oxygen species production and overactivation of the mitogen-activated protein kinase pathway. Mol Pharmacol 73: 1491-1501, 2008.

12. Vaupel P: Oxygenation of human tumors. Strahlenther Onkol 166: 377-386, 1990.

13. Mayer R, Hamilton-Farrell MR, van der Kleij AJ, Schmutz J, Granström G, Sicko Z, Melamed Y, Carl UM, Hartmann KA, Jansen EC, et al: Hyperbaric oxygen and radiotherapy. Strahlenther Onkol 181: 113-123, 2005.

14. Becker A, Kuhnt T, Liedtke H, Krivokuca A, Bloching M and Dunst J: Oxygenation measurements in head and neck cancers during hyperbaric oxygenation. Strahlenther Onkol 178: 105-108, 2002.

15. Brizel DM, Hage WD, Dodge RK, Munley MT, Piantadosi CA and Dewhirst MW: Hyperbaric oxygen improves tumor radiation response significantly more than carbogen/nicotinamide. Radiat Res 147: 715-720, 1997.

16. Hartmann KA, van der Kleij AJ, Carl UM, Hulshof MC, Willers R and Sminia P: Effects of hyperbaric oxygen and normobaric carbogen on the radiation response of the rat rhabdomyosarcoma R1H. Int J Radiat Oncol Biol Phys 51: 1037-1044, 2001.

17. Nordsmark M, Maxwell RJ, Horsman MR, Bentzen SM and Overgaard J: The effect of hypoxia and hyperoxia on nucleoside triphosphate/inorganic phosphate, $\mathrm{pO} 2$ and radiation response in an experimental tumour model. Br J Cancer 76: 1432-1439, 1997.

18. Pietrofesa RA, Velalopoulou A, Lehman SL, Arguiri E, Solomides P, Koch CJ, Mishra OP, Koumenis C, Goodwin TJ and Christofidou-Solomidou M: Novel double-hit model of radiation and hyperoxia-induced oxidative cell damage relevant to space travel. Int J Mol Sci 17: 953, 2016

19. Hofer T, Desbaillets I, Hopfl G, Wenger RH and Gassmann M: Characterization of HIF-1 alpha overexpressing HeLa cells and implications for gene therapy. Comp Biochem Physiol C Toxicol Pharmacol 133: 475-481, 2002.

20. Masoud GN and Li W: HIF-1 $\alpha$ pathway: Role, regulation and intervention for cancer therapy. Acta Pharm Sin B 5: 378-389, 2015.
21. Park JH, Yoon J and Park B: Pomolic acid suppresses HIF1 $\alpha /$ VEGF-mediated angiogenesis by targeting p38-MAPK and mTOR signaling cascades. Phytomedicine 23: 1716-1726, 2016.

22. Chen JY, Gu ZJ, Wu MX, Yang Y, Zhang JH, Ou JS, Zuo ZY, Wang JF and Chen YX: C-reactive protein can upregulate VEGF expression to promote ADSC-induced angiogenesis by activating HIF-1 $\alpha$ via CD64/PI3k/Akt and MAPK/ERK signaling pathways. Stem Cell Res Ther 7: 114, 2016.

23. Miyasaka A, Oda K, Ikeda Y, Sone K, Fukuda T, Inaba K, Makii C, Enomoto A, Hosoya N, Tanikawa M, et al: PI3K/mTOR pathway inhibition overcomes radioresistance via suppression of the HIF1- $\alpha$ /VEGF pathway in endometrial cancer. Gynecol Oncol 138: 174-180, 2015

24. Fechner G, Dederichs F, Schmidt D, Muller S, Vaupel P and Albers P: Hyperoxia-induced improvement of the in vitro response to gemcitabine in transitional cell carcinoma. Anticancer Res 25: 3413-3418, 2005.

25. Liu Q, He X, Liu Y, Du B, Wang X, Zhang W, Jia P, Dong J, Ma J, Wang X, et al: NADPH oxidase-mediated generation of reactive oxygen species: A new mechanism for X-ray-induced HeLa cell death. Biochem Biophys Res Commun 377: 775-779, 2008.

26. Lu J, Suzuki T, Lu S and Suzuki N: Involvement of glyceraldehyde-3-phosphate dehydrogenase in the X-Ray resistance of HeLa cells. Biosci Biotechnol Biochem 72: 2432-2435, 2008.

27. Lake AC, Vassy R, Di Benedetto M, Lavigne D, Visage CL, Perret GY and Letourneur D: Low molecular weight fucoidan increases VEGF165-induced endothelial cell migration by enhancing VEGF165 binding to VEGFR-2 and NRP1. J Biol Chem 281: 37844-37852, 2006.

28. Wu XJ, Zhu JW, Jing J, Xue D, Liu H, Zheng M and Lu ZF: VEGF165 modulates proliferation, adhesion, migration and differentiation of cultured human outer root sheath cells from central hair follicle epithelium through VEGFR-2 activation in vitro. J Dermatol Sci 73: 152-160, 2014.

29. Zhang H, Han Y, Tao J, Liu S, Yan C and Li S: Cellular repressor of E1A-stimulated genes regulates vascular endothelial cell migration by the ILK/AKT/mTOR/VEGF(165) signaling pathway. Exp Cell Res 317: 2904-2913, 2011.

30. Tsuzuki T, Okada H, Shindoh H, Shimoi K, Nishigaki A and Kanzaki H: Effects of the hypoxia-inducible factor-1 inhibitor echinomycin on vascular endothelial growth factor production and apoptosis in human ectopic endometriotic stromal cells. Gynecol Endocrinol 32: 323-328, 2016.

31. Walsh CM, Chvanov M, Haynes LP, Petersen OH, Tepikin AV and Burgoyne RD: Role of phosphoinositides in STIM1 dynamics and store-operated calcium entry. Biochem J 425: 159-168, 2009.

32. Ma S, Musa T and Bag J: Reduced stability of mitogen-activated protein kinase kinase-2 mRNA and phosphorylation of poly(A)-binding protein (PABP) in cells overexpressing PABP. J Biol Chem 281: 3145-3156, 2006.

33. Lin C, McGough R, Aswad B, Block JA and Terek R: Hypoxia induces HIF-1alpha and VEGF expression in chondrosarcoma cells and chondrocytes. J Orthop Res 22: 1175-1181, 2004

34. Fu Z, Chen D, Cheng H and Wang F: Hypoxia-inducible factor-1 $\alpha$ protects cervical carcinoma cells from apoptosis induced by radiation via modulation of vascular endothelial growth factor and p53 under hypoxia. Med Sci Monitor 21: 318-325, 2015.

35. Shibuya M: VEGF-VEGFR system as a target for suppressing inflammation and other diseases. Endocr Metab Immune Disord Drug Targets 15: 135-144, 2015.

36. Gupta AK, Bakanauskas VJ, Cerniglia GJ, Cheng Y, Bernhard EJ, Muschel RJ and McKenna WG: The Ras radiation resistance pathway. Cancer Res 61: 4278-4282, 2001

37. McKenna WG, Muschel RJ, Gupta AK, Hahn SM and Bernhard EJ: The RAS signal transduction pathway and its role in radiation sensitivity. Oncogene 22: 5866-5875, 2003.

38. Shimura T, Kakuda S, Ochiai Y, Kuwahara Y, Takai Y and Fukumoto M: Targeting the AKT/GSK3beta/cyclin D1/Cdk4 survival signaling pathway for eradication of tumor radioresistance acquired by fractionated radiotherapy. Int J Radiat Oncol Biol Phys 80: 540-548, 2011.

39. Vaupel P and Mayer A: Hypoxia in cancer: Significance and impact on clinical outcome. Cancer Metastasis Rev 26: 225-239, 2007.

40. Liao D and Johnson RS: Hypoxia: A key regulator of angiogenesis in cancer. Cancer Metastasis Rev 26: 281-290, 2007.

41. Thomlinson RH and Gray LH: The histological structure of some human lung cancers and the possible implications for radiotherapy. Br J Cancer 9: 539-549, 1955. 
42. Bennett MH, Feldmeier J, Smee R and Milross C: Hyperbaric oxygenation for tumour sensitisation to radiotherapy. Cochrane Database Syst Rev 4: CD005007, 2018.

43. Gorski DH, Beckett MA, Jaskowiak NT, Calvin DP, Mauceri HJ Salloum RM, Seetharam S, Koons A, Hari DM, Kufe DW and Weichselbaum RR: Blockage of the vascular endothelial growth factor stress response increases the antitumor effects of ionizing radiation. Cancer Res 59: 3374-3378, 1999.

44. Ferrara N, Gerber HP and LeCouter J: The biology of VEGF and its receptors. Nat Med 9: 669-676, 2003.

45. Hiratsuka S, Minowa O, Kuno J, Noda T and Shibuya M: Flt-1 lacking the tyrosine kinase domain is sufficient for normal development and angiogenesis in mice. Proc Natl Acad Sci USA 95: 9349-9354, 1998.

46. Selvaraj D, Gangadharan V, Michalski CW, Kurejova M, Stösser S, Srivastava K, Schweizerhof M, Waltenberger J, Ferrara N, Heppenstall P, et al: A functional role for VEGFR1 expressed in peripheral sensory neurons in cancer pain. Cancer Cell 27: 780-796, 2015.

47. Ding ZY, Huang YJ, Tang JD, Li G, Jiang PQ and Wu HT: Silencing of hypoxia-inducible factor-1 $\alpha$ promotes thyroid cancer cell apoptosis and inhibits invasion by downregulating WWP2, WWP9, VEGF and VEGFR2. Exp Ther Med 12: 3735-3741, 2016.
48. Gupta VK, Jaskowiak NT, Beckett MA, Mauceri HJ, Grunstein J, Johnson RS, Calvin DA, Nodzenski E, Pejovic M, Kufe DW, et al: Vascular endothelial growth factor enhances endothelial cell survival and tumor radioresistance. Cancer J 8: 47-54, 2002.

49. Chen YA, Tzeng DTW, Huang YP, Lin CJ, Lo UG, Wu CL, Lin H, Hsieh JT, Tang CH and Lai CH: Antrocin sensitizes prostate cancer cells to radiotherapy through inhibiting PI3K/AKT and MAPK signaling pathways. Cancers (Basel) 11: 34, 2018.

50. Mazzatti DJ, Lee YJ, Helt CE, O'Reilly MA and Keng PC: p53 modulates radiation sensitivity independent of p21 transcriptional activation. Am J Clin Oncol 28: 43-50, 2005.

51. Lee KB, Kim KR, Huh TL and Lee YM: Proton induces apoptosis of hypoxic tumor cells by the p53-dependent and p38/JNK MAPK signaling pathways. Int J Oncol 33: 1247-1256, 2008.

52. Yoon TM, Kim SA, Lee DH, Lee JK, Park YL, Lee KH, Chung IJ, Joo YE and Lim SC: EGR1 regulates radiation-induced apoptosis in head and neck squamous cell carcinoma. Oncol Rep 33: $1717-1722,2015$.

(i) (9) This work is licensed under a Creative Commons EY No ND Attribution-NonCommercial-NoDerivatives 4.0 International (CC BY-NC-ND 4.0) License. 